\title{
Electrical Threshold of the Human Heart
}

\author{
J. G. DAVIES AND EDGAR SOWTON \\ From the Cardiac Department, St. George's Hospital, London S.W.1
}

When patients with Stokes-Adams disease are treated with artificial pacemakers the threshold for stimulation of the heart rises initially (Senning, 1959; Stephenson, 1960; Zoll et al., 1961; Kantrowitz et al., 1962) and threshold values of up to 200 volts have been reported (Dittmar, Friese, and Holder, 1962). The threshold may fall again after an initial rise (Chardack, Gage, and Greatbatch, 1960; Simpson et al., 1962) and usually reaches a plateau after a few weeks. This paper reports the results of measurements of acute and chronic thresholds in $\mathbf{5 0}$ patients.

\section{Patients AND Methods}

The patients were being treated by artificial pacemaking for Stokes-Adams disease, and after discharge from hospital they attended a pacemaker clinic. Fourteen patients were being paced with endocardial stimulation via electrode catheters, 8 had small external pacemakers connected to electrodes on the surface of the heart, and 28 had implanted self-contained pacemakers connected to epicardial electrodes.

The electrode catheters wer positioned so that the tip contact lay in the apex of the right ventricle and was impacted amongst the trabeculæ (Sowton and Davies, 1964). The electrode of the unipolar catheter* was of platinum and comprised the terminal $2 \mathrm{~mm}$. of the catheter which was of $2 \mathrm{~mm}$. diameter. Bipolar electrode catheters had, in addition, a $2 \mathrm{~mm}$. ring of platinum set $1 \mathrm{~cm}$. back from the tip forming a second electrode. $t$ The epicardial electrodes consisted of a triple coil of stainless steel wire (specification EN58J) of $0.85 \mathrm{~mm}$. total outside diameter, so arranged as to expose about $10 \mathrm{~mm}$. of the coil to the epicardium $¥$ (Fig. 1). For unipolar epicardial stimulation, one such electrode was surgically attached near the apex of the heart on a fat-free area of the anterior surface of the right or left ventricle (Siddons, 1963), and the other pole of the pace-

Received June 21, 1965.

* Type C50, United States Catheter Corp., Glens Falls, New York.

† Type C51, United States Catheter Corp., Glens Falls, New York.

‡ Devices Ltd., Welwyn Garden City, Herts. maker was attached to an indifferent electrode consisting of a coiled stainless steel loop, $0.85 \mathrm{~mm}$. diameter, buried in the tissues of the anterior abdominal wall, with $6 \mathrm{~cm}$. length exposed free of insulation. For bipolar stimulation two epicardial electrodes were attached to the heart about $2 \mathrm{~cm}$. apart. Two patients had intramural electrodes, consisting of braided stainless steel wire passing for a distance of about $2 \mathrm{~cm}$. within the wall of the left ventricle but not entering the ventricular cavity.

Thresholds were measured in all patients at the onset of pacing and when the internal units were replaced. In addition, patients with external units were studied at routine visits to the pacemaker clinic.

The pacemaker used for threshold measurements was designed by one of us (J.G.D.), and has an output impedance of approximately $50 \mathrm{ohms}$, with a variable rate, voltage, and impulse duration. Current was measured as the voltage drop across a $10 \mathrm{ohm}$ resistor within the pacemaker, and values for current, voltage, and impulse duration were obtained from photographs of the image displayed on a Tetronix type 551 oscilloscope (Fig. 2). Threshold values were determined by slow reduction of the stimulating voltage (or current) until pacing ceased, the end-point being detected by means of a battery-driven pulse monitor or an electrocardiogram. The impulse wave form used was initially a biphasic square wave and the figures quoted in this paper refer to unipolar cathodal stimulation unless stated otherwise. In the calculation of energy transferred to the load the phase angle has been ignored, since this was found to affect the result by less than 2 per cent. No significant differences were found in threshold values when the pacemaker rate was varied over the range $50-90$ beats a minute, and so no attempt to standardize this variable was made.

In the presence of infection around the electrodes, there was no clear end-point, and accurate threshold measurements could not be made; when threshold values varied widely from moment to moment, the cause was invariably an unstable electrical contact somewhere in the pacing circuit, usually at the heart, and no readings taken under these circumstances have been included in the tables presented here.

Clinical and hæmodynamic data on this series of patients are reported elsewhere (Siddons, 1963; Sowton, 1964, 1965; Harris et al., 1965). 


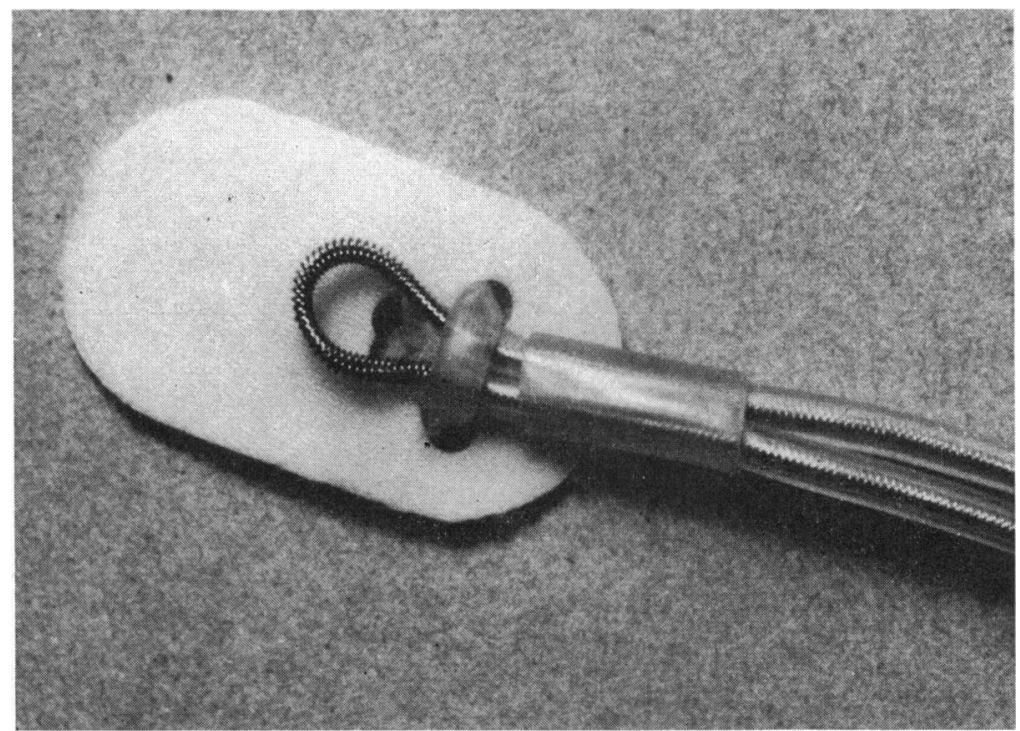

FIG. 1.-Epicardial electrode. About $10 \mathrm{~mm}$. of a triple coil of stainless steel (or platinum) wire was exposed to the epicardial surface of the heart. The coil runs freely in silastic insulating tubing.

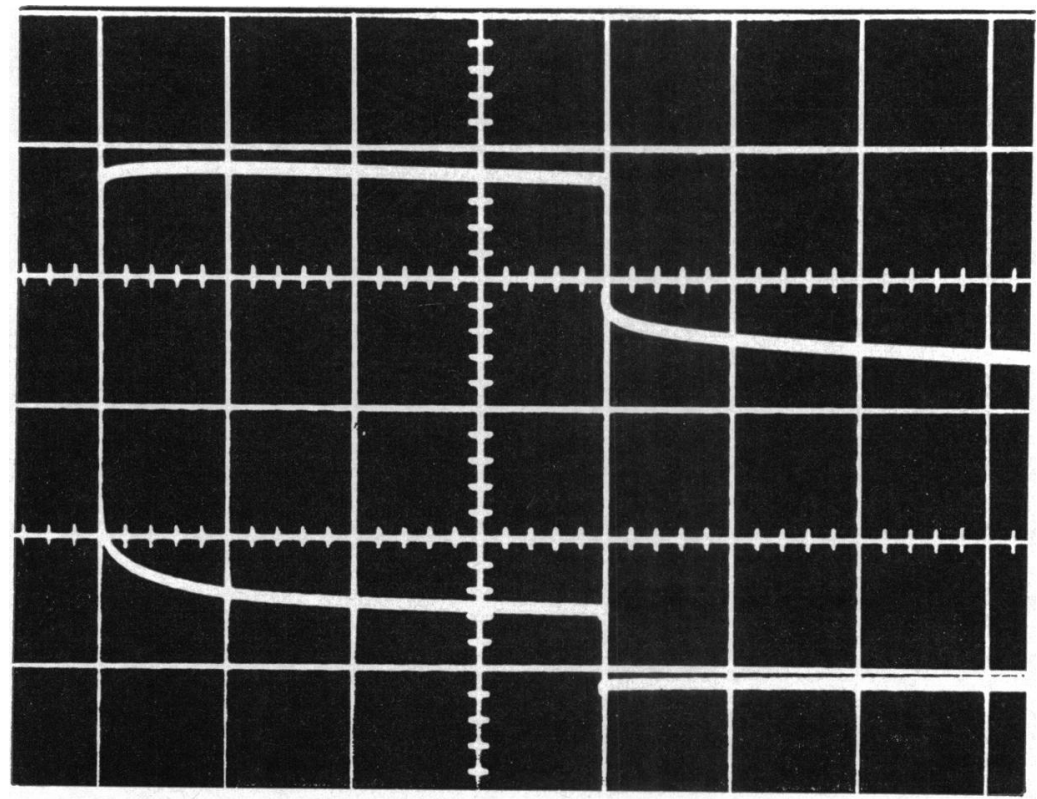

FIG. 2.-Photograph of the voltage (upper trace) and current (lower trace) wave forms as displayed on the oscilloscope. Horizontal scale: each large division represents 0.5 millisecond.

\section{ResUlts}

Mean voltage thresholds for a 2 msec. impulse under different conditions are shown in Table I.
The threshold voltages were lower for endocardial (catheter) than for epicardial stimulation, and in all cases the final values were higher than the initial values. In 4 patients whose results have not been 
TABLE I

MEAN VALUES FOR THRESHOLD VOLTAGES

\begin{tabular}{|c|c|c|c|c|c|c|c|}
\hline \multicolumn{4}{|c|}{ Type of stimulation } & \multirow{2}{*}{ 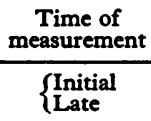 } & \multirow{2}{*}{$\begin{array}{c}\text { Threshold mean } \\
\begin{array}{c}0.48 \\
1.62\end{array}\end{array}$} & \multirow{2}{*}{$\begin{array}{c}\text { Voltage range } \\
\begin{array}{l}0.25-1 \cdot 0 \\
0.85-2.5\end{array}\end{array}$} & \multirow{2}{*}{$\begin{array}{c}\text { No. of patients } \\
14 \\
12\end{array}$} \\
\hline Endocardial unipolar & $\cdots$ & $\cdots$ & $\cdots$ & & & & \\
\hline Endocardial bipolar & $\cdots$ & $\cdots$ & $\cdots$ & $\left\{\begin{array}{l}\text { Initial } \\
\text { Late }\end{array}\right.$ & $\begin{array}{l}0.55 \\
1.80\end{array}$ & $\begin{array}{l}0.30-0.95 \\
0.70-2.8\end{array}$ & $\begin{array}{l}6 \\
3\end{array}$ \\
\hline Intramural unipolar & $\cdots$ & $\cdots$ & $\cdots$ & $\left\{\begin{array}{l}\text { Initial } \\
\text { Late }\end{array}\right.$ & $\begin{array}{l}0.85 \\
1.50\end{array}$ & 0.70 and 1.0 & $\begin{array}{l}2 \\
1\end{array}$ \\
\hline Epicardial unipolar & $\cdots$ & $\cdots$ & $\cdots$ & $\left\{\begin{array}{l}\text { Initial } \\
\text { Late }\end{array}\right.$ & $\begin{array}{l}1.41 \\
2.03\end{array}$ & $\begin{array}{l}0.40-2 \cdot 5 \\
0.80-2 \cdot 8\end{array}$ & $\begin{array}{l}11 \\
11\end{array}$ \\
\hline Epicardial bipolar .. & $\cdots$ & $\bullet$ & $\cdots$ & $\left\{\begin{array}{l}\text { Initial } \\
\text { Late }\end{array}\right.$ & $\begin{array}{l}1 \cdot 80 \\
2 \cdot 20\end{array}$ & $\overline{-}$ & $\begin{array}{l}1 \\
1\end{array}$ \\
\hline
\end{tabular}

The "initial" values were taken within a few hours of attachment of the electrodes to the heart, and the "late" values refer to the final threshold level after several weeks or months.

included in Table $I$, stimulation was carried out via an electrode catheter placed in the coronary sinus and in each case there was a rapid rise in threshold requirements to unacceptable levels (over 9 volts).

The threshold voltages corresponding to different stimulus durations were investigated in 17 patients, several of them having more than one series of measurements taken. Fig. 3 shows strengthduration curves obtained shortly after a unipolar electrode catheter had been inserted into the right ventricle; it shows that the threshold was considerably higher when the electrode tip was the positive pole than when it was the negative pole for all stimulus durations. Repeated measurements showed that the shape of the curves changed little with time but the rheobase voltage increased until the threshold plateau was reached (Fig. 4).

When the electrodes were on the epicardium the strength-duration curves differed in shape from those produced by endocardial stimulation, and typical results for the same patient are illustrated in Fig. 5. The differences in shape were very pronounced when infection was present around the epicardial electrode.

When the catheter electrodes were not firmly in contact with the ventricular wall, it proved impossible to obtain strength-duration curves owing to wide variations of threshold, and values above 8

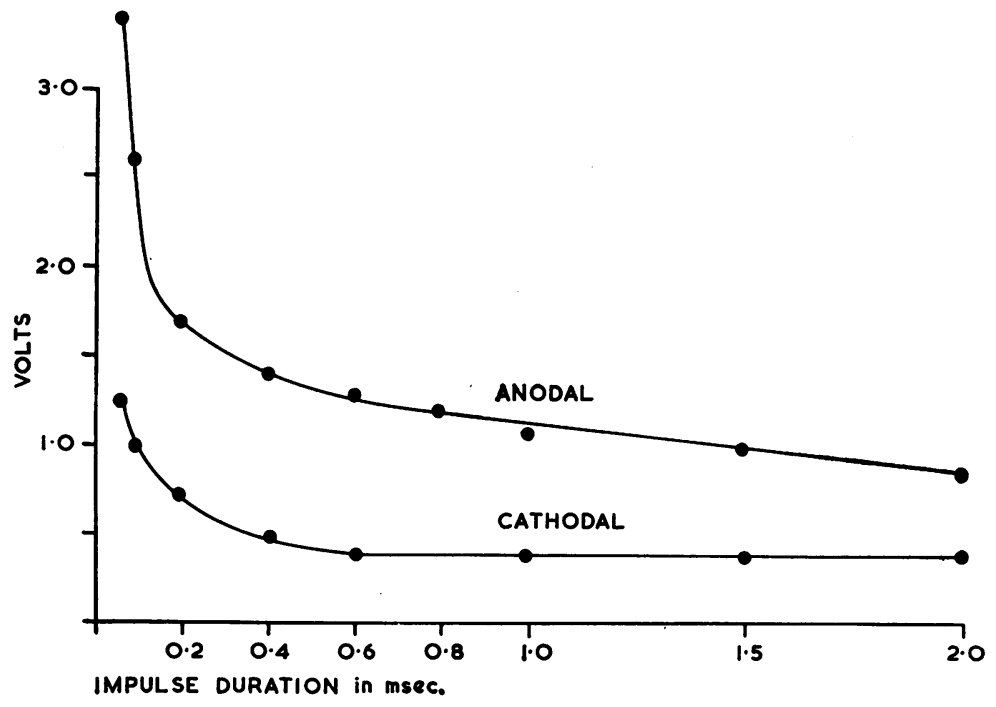

FIG. 3.-Unipolar endocardial stimulation: voltage strength-duration curves obtained by stimulation shortly after a unipolar electrode catheter had been inserted in the right ventricle. The thresholds were considerably higher when the electrode tip was the anode than when it was the cathode. 


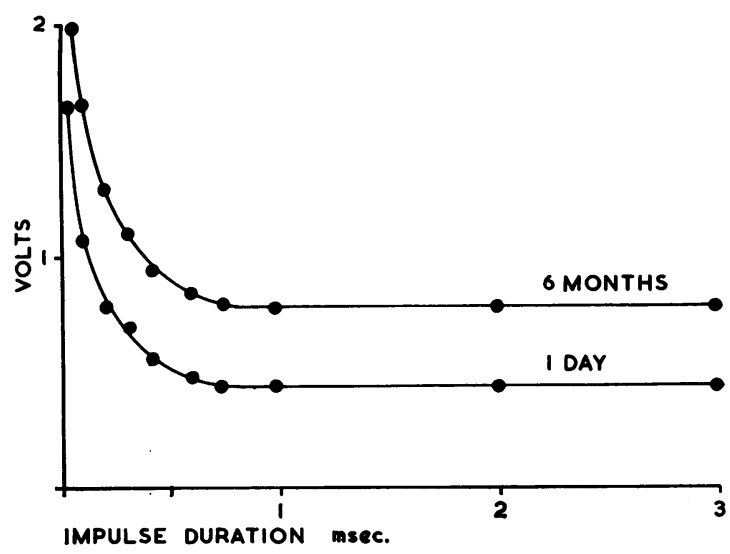

FIG. 4.-Unipolar endocardial stimulation: voltage strength-duration curves obtained one day and six months after insertion of the unipolar electrode catheter into the right ventricle. Cathodal stimulation was used throughout.

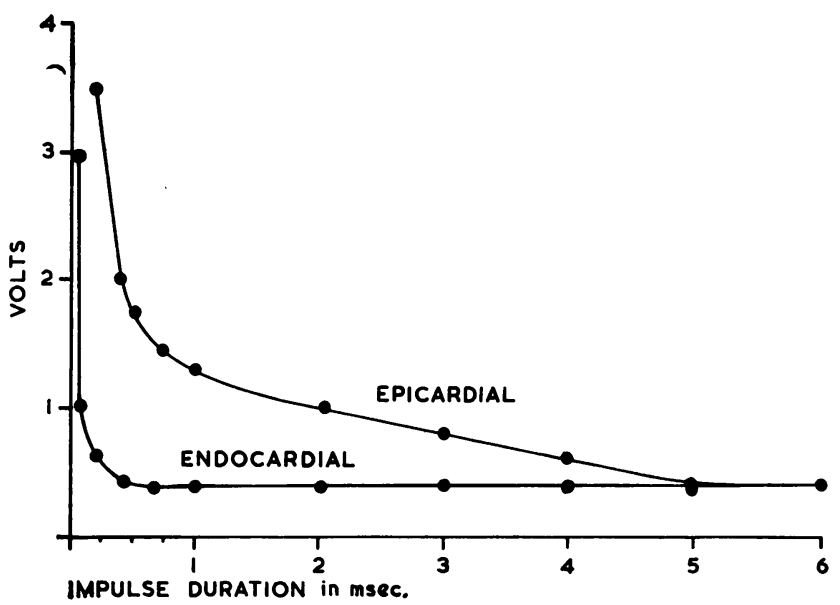

FIG. 5.-Unipolar stimulation: comparison of voltage strength duration curves for epicardial and endocardial unipolar stimulation. Both records were taken shortly after the electrodes had been attached to the heart. The threshold for epicardial stimulation was higher than for endocardial stimulation for all pulse durations

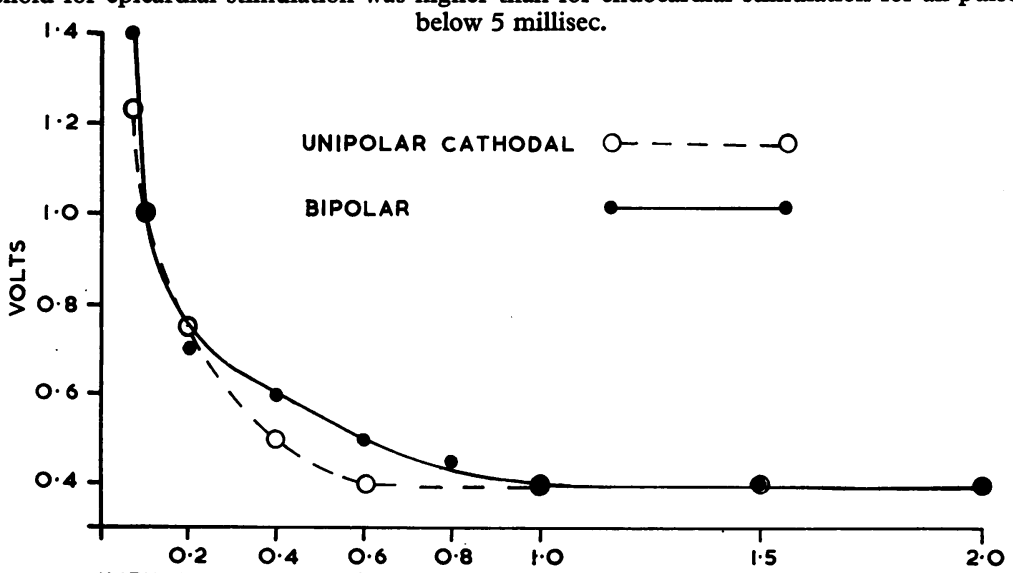

IMPULSE DURATION in msec.

Frg. 6.-Endocardial stimulation: comparison of unipolar and bipolar cathodal stimulation when the impulse was applied to the endocardial surface of the right ventricle. There was no significant difference between the two systems. 
volts ( $2 \mathrm{msec}$. impulse) were often recorded when the electrodes, either unipolar or bipolar, were free in the right ventricular cavity. In 2 patients with the catheter tip impacted amongst the trabeculæ, strength-duration curves were compared for unipolar and bipolar pacing. There was no significant difference between the two systems (Fig. 6), and this finding was confirmed by partial curves on 4 additional patients. Investigation of epicardial unipolar and bipolar stimulation in a further 4 patients also gave a similar result.

Current strength-duration curves were obtained on 11 occasions in 8 patients and were very similar in shape to the voltage strength-duration curves (Fig. 7). The mean values of rheobase and chronaxie obtained from 36 strength-duration curves under different conditions are given in Table II; values recorded in the presence of infection around the electrodes have been excluded.
Calculations of the threshold energy delivered to the load at different impulse durations were made for 42 investigations in 24 patients. A typical graph of threshold energy and impulse duration is illustrated in Fig. 8 and shows that the energy was approximately constant for impulses between 0.3 msec. and 1.0 msec. Similar graphs were plotted for the other 23 patients and the mean threshold energy corresponding to the flat portions of the graphs obtained. These results are presented in Table III.

In the presence of infection around epicardial electrodes, no threshold plateau was reached, and the requirements showed a steady increase, often with marked day-to-day variation. Some of these patients had thresholds for epicardial electrodes of over 200 microjoules, and we consider that a threshold value of 50 microjoules or over suggests that infection has occurred. In 3 patients of this series

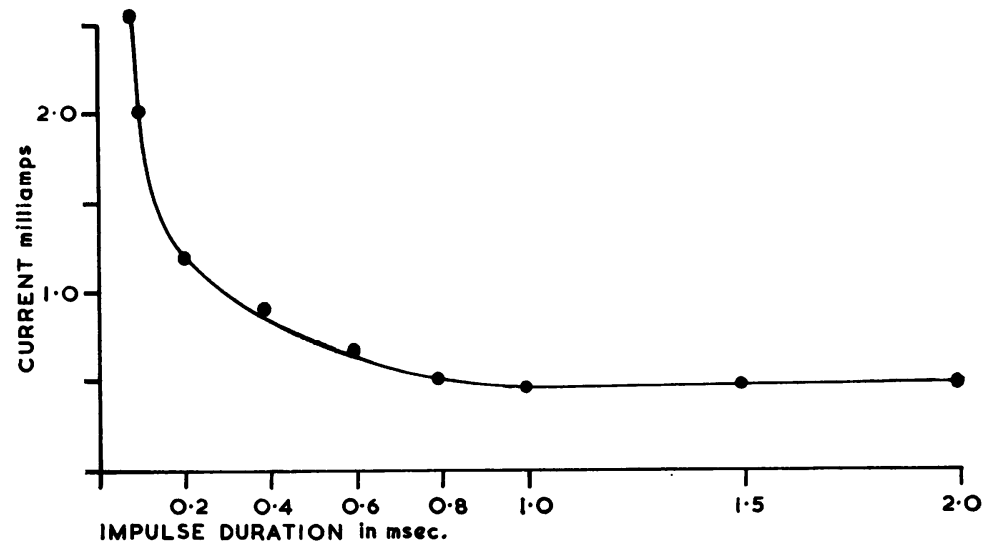

FIG. 7.-Bipolar endocardial stimulation: current strength-duration curve obtained shortly after a bipolar electrode catheter had been inserted into the right ventricle.

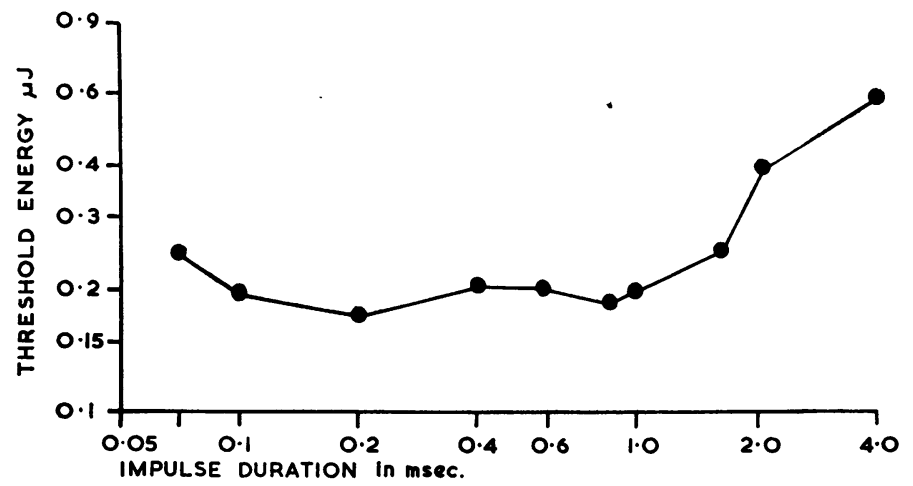

FIG. 8.-Bipolar endocardial stimulation: relation of impulse duration to threshold energy for bipolar endocardial stimulation shortly after the catheter had been inserted into the right ventricle. The energy delivered to the load was approximately constant for impulses of 0.1 to 1.0 millisecond. Log-log scales. 
TABLE II

MEAN VALUES FOR RHEOBASE AND CHRONAXIE FOR THE HUMAN HEART

\begin{tabular}{|c|c|c|c|c|c|c|c|c|}
\hline \multirow{2}{*}{$\begin{array}{c}\begin{array}{c}\text { Type of } \\
\text { strength-duration } \\
\text { curve }\end{array} \\
\text { Voltage }\end{array}$} & \multicolumn{4}{|c|}{ Type of stimulation } & \multirow{2}{*}{\begin{tabular}{|l}
$\begin{array}{c}\text { Time of } \\
\text { recording }\end{array}$ \\
\{lnitial \\
Late
\end{tabular}} & \multirow{2}{*}{$\begin{array}{c}\begin{array}{c}\text { Rheobase } \\
\text { (volts or milli- } \\
\text { amps) }\end{array} \\
\begin{array}{c}0.45 \\
1.5\end{array}\end{array}$} & \multirow{2}{*}{$\begin{array}{c}\begin{array}{c}\text { Chronaxie } \\
\text { (millisecond) }\end{array} \\
\begin{array}{l}0.35 \\
0.23\end{array}\end{array}$} & \multirow{2}{*}{$\frac{\text { No. of patients }}{}$} \\
\hline & Endocardial unipolar & & $\cdots$ & $\cdots$ & & & & \\
\hline " & Endocardial bipolar & $\cdots$ & .. & $\cdots$ & Initial & 0.40 & 0.20 & 1 \\
\hline 乌 & Epicardial unipolar & $\cdots$ & $\cdots$ & $\cdots$ & $\left\{\begin{array}{l}\text { Initial } \\
\text { Late }\end{array}\right.$ & $\begin{array}{l}0.47 \\
2.4\end{array}$ & $\begin{array}{l}1 \cdot 1 \\
0.60\end{array}$ & $\begin{array}{l}3 \\
2\end{array}$ \\
\hline " & Epicardial bipolar & $\cdots$ & $\cdots$ & $\cdots$ & $\left\{\begin{array}{l}\text { Initial } \\
\text { Late }\end{array}\right.$ & $\begin{array}{l}1 \cdot 8 \\
2 \cdot 2\end{array}$ & $\begin{array}{l}0.75 \\
0.70\end{array}$ & $\begin{array}{l}2 \\
2\end{array}$ \\
\hline " & Intramural unipolar & $\cdots$ & $\cdots$ & $\cdots$ & $\left\{\begin{array}{l}\text { Initial } \\
\text { Late }\end{array}\right.$ & $\begin{array}{l}0.80 \\
1.5\end{array}$ & $\begin{array}{l}0.70 \\
0.30\end{array}$ & $\begin{array}{l}2 \\
1\end{array}$ \\
\hline Current & Endocardial unipolar & $\cdots$ & $\cdots$ & $\cdots$ & $\left\{\begin{array}{l}\text { Initial } \\
\text { Late }\end{array}\right.$ & $\begin{array}{l}0.45 \\
0.80\end{array}$ & $\begin{array}{l}0.20 \\
1 \cdot 1\end{array}$ & $\begin{array}{l}1 \\
3\end{array}$ \\
\hline " & Endocardial bipolar & $\cdots$ & . & $\cdots$ & Initial & 0.45 & 0.30 & 1 \\
\hline " & Epicardial unipolar & $\cdots$ & $\cdots$ & . & Initial & $1 \cdot 2$ & 0.93 & 3 \\
\hline פ & Epicardial bipolar & $\cdots$ & - & . & Late & $3 \cdot 8$ & 0.80 & 1 \\
\hline э & Intramural unipolar & $\cdots$ & $\cdots$ & . & Initial & 0.90 & $1 \cdot 0$ & 1 \\
\hline
\end{tabular}

TABLE III

THRESHOLD ENERGY INITIATING CONTRACTION

\begin{tabular}{|c|c|c|c|c|c|c|c|}
\hline \multicolumn{4}{|c|}{ Type of simulation } & \multirow[t]{2}{*}{ Time of measurement } & \multicolumn{2}{|c|}{$\begin{array}{c}\text { Threshold energy } \\
\text { (microjoules) }\end{array}$} & \multirow[t]{2}{*}{ Number of patients } \\
\hline & & & & & Mean & Range & \\
\hline Endocardial unipolar & $\cdots$ & . & $\cdots$ & $\left\{\begin{array}{l}\text { Initial } \\
\text { Late }\end{array}\right.$ & $\begin{array}{l}0.58 \\
4.9\end{array}$ & $\begin{array}{l}0.13-1.0 \\
0.70-13.0\end{array}$ & $\begin{array}{r}7 \\
12\end{array}$ \\
\hline Endocardial bipolar & $\cdots$ & . & . & $\left\{\begin{array}{l}\text { Initial } \\
\text { Late }\end{array}\right.$ & $\begin{array}{l}0.37 \\
4.5\end{array}$ & $\begin{array}{c}0.20-0.71 \\
2.5 \text { and } 6.5\end{array}$ & $\begin{array}{l}3 \\
2\end{array}$ \\
\hline Intramural unipolar & $\cdots$ & $\cdots$ & $\cdots$ & $\left\{\begin{array}{l}\text { Initial } \\
\text { Inate }\end{array}\right.$ & $15^{2 \cdot 3}$ & 1.9 and 2.6 & $\begin{array}{l}2 \\
1\end{array}$ \\
\hline Epicardial unipolar & $\cdots$ & $\cdots$ & $\cdots$ & $\left\{\begin{array}{l}\text { Initial } \\
\text { Late }\end{array}\right.$ & $22 \cdot 0$ & $\begin{array}{r}1 \cdot 5-2 \cdot 9 \\
4 \cdot 5-34\end{array}$ & $\begin{array}{l}3 \\
4\end{array}$ \\
\hline Epicardial bipolar ... & $\cdots$ & . & $\cdots$ & Late & 20 & 一 & 1 \\
\hline
\end{tabular}

the threshold rose above 50 microjoules in the apparent absence of infection, and in 2 of these the epicardial electrode was subsequently found to be making contact with the epicardium over a length of the coiled wire considerably in excess of $10 \mathrm{~mm}$.

\section{Discussion}

The threshold for electrical stimulation is often described in terms of voltage or current, but these terms are meaningless unless the impulse duration is given, though in clinical practice this can usually be assumed to be of the order of $2 \mathrm{msec}$. The use of impulse energy is theoretically attractive since this is usually almost constant for a wide range of impulse widths, but unless the corresponding chronaxie and rheobase values are known the threshold information is incomplete, and there is no simple, completely satisfactory, way in which the cardiac threshold can be adequately expressed. A possible source of error in most threshold measurements is that unknown losses may occur due to high resistance faults or alternative current pathways in the catheter or electrode, and the results we present here may be influenced by this factor though on clinical grounds we consider it unlikely since pacing was satisfactory for long periods in all patients.

A variety of early reports concerning the threshold for epicardial and intramural stimulation claimed that bipolar electrodes were considerably superior to unipolar electrodes, resulting in a threshold that stabilized sooner and at a lower level (Hunter et al., 1959; Chardack et al., 1960), though other workers were unable to show any difference in the sensitivity 
of the heart to unipolar or bipolar stimulation (Lillehei et al., 1960; Zoll et al., 1961; Keller, 1964). Our results are in agreement with a later report from Chardack's group (Chardack, Gage, and Greatbatch, 1961), showing that the superior performance of the bipolar electrodes was due to the high current density secondary to their shape and not to their bipolar properties; but we cannot confirm that this is true only for deep intramural electrodes. Our experience is similar to that of Elmqvist et al. (1963) who found epicardial electrodes satisfactory.

When the thresholds were expressed as energy, the values were approximately constant and not dependent upon pulse width over a fairly wide range, though we noticed an increase in requirements for very short and very long impulses. Although the values increased, the relation between energy and pulse width was unaffected by the length of time pacing had been continued, and the threshold increased in the same way whether the electrodes were actually used for stimulation or not. These results are in keeping with the reports of Raillard (1962) on human hearts, and with results found on dogs by Nash et al. (1962).

It has long been known from animal experiments that cathodal stimulation of the heart will mimic the normal depolarization potential (Hoffman and Cranefield, 1964), and so it is not surprising that in this study the threshold energy was considerably higher for anodal unipolar stimulation than for cathodal, an effect that has also been noted by many other observers. As the end-point for anodal stimulation was often ill defined, the values are unreliable and have not been given here in detail, but the threshold energies for the patient whose strength duration curves are illustrated in Fig. 3 were 0.13 microjoules for cathodal and 2.10 microjoules for anodal stimulation, a ratio of $1: 16$.

If the electrodes were applied to fibrotic areas of the heart a rather more powerful stimulus was needed than elsewhere to initiate contraction, but pacing could be carried out successfully, as noted also by Weale, Deuchar, and Nightingale (1960) and by Albert et al. (1962).

Zucker et al. (1963) showed that in dogs pacing with bipolar electrode catheters was satisfactory, even when both electrodes were shielded to prevent direct contact with the myocardium, and they postulated that the heart was responding to the electrical field set up around the catheter tip. In our experience catheter pacing in human subjects is unsatisfactory unless the electrodes are touching or very near to the endocardial surface, and on several occasions we have noted threshold requirements varying from half a volt up to 9 volts as a bipolar catheter tip moved in the bloodstream within the right ventricle without either electrode crossing the tricuspid or pulmonary valve. The probable explanation of this disparity lies in the fact that a dog's ventricle is small enough for the muscle to be stimulated wherever the tip of a bipolar catheter lies, but the electrical field is not intense enough for stable pacing to be achieved when the catheter tip is more than a critical distance away from the myocardium, and so in the larger human heart unstable pacing can result.

Thresholds found in this study were considerably lower whenever the impulse was applied to the endocardium rather than to the epicardium, and the explanation of this finding is not yet clear. It is possible that the difference in the materials and anatomy of the endocardial and epicardial electrodes was sufficient to account for the variation, and it has been shown (Mansfield and Cole, 1963) that decreasing electrode area may decrease current threshold in an almost linear fashion. An alternative hypothesis is that the conducting tissue was stimulated directly during endocardial pacing while the epicardial electrodes led to stimulation of cardiac muscle. The work of Zarnstorff et al. (1962) at open heart surgery confirmed that the conducting tissue had a lower threshold than cardiac muscle, and this interpretation is supported to some extent by the relative shapes of the two strength duration curves illustrated in Fig. 5. The extremely short impulses capable of initiating ventricular contraction when applied to the endocardium are also compatible with this latter view; the shortest impulse with which we were able to pace the heart via an electrode catheter was 3 microseconds, and the minimum threshold current we found was 400 microamps, while the minimum voltage capable of stimulating the heart irrespective of pulse duration was 250 millivolts. Feldman (1963) also reported that endocardial stimulation of the human heart was possible with short duration impulses and concluded that conducting tissue was probably stimulated directly.

Many of the results reported here are in agreement with the acute experiments on animals' hearts which are reported in detail by Brooks et al. (1955) and by Hoffman and Cranefield (1960), as well as with the studies on stimulation of dogs' hearts reported by Nash (1964) and by Albert et al. (1964). The strength duration curves reported here are in agreement with those obtained by Weale et al. (1960) from a 72-year-old man with postinfarction heart block, and indicate that an impulse of 1-2 milliseconds is satisfactory for epicardial or intramural stimulation, though considerably shorter impulses can be used for endocardial stimulation. 
Most commercially available units provide impulses within this range, though pulses as long as $\mathbf{4 0}$ milliseconds (Tsuboi and Ebina, 1960) or even 100 milliseconds (Stephenson et al., 1959) have been recommended in the past for clinical use. The values we report for chronaxie are rather shorter than those noted by Feldman and Kantrowitz (1963) on 3 human subjects, but these differences are probably related to the type and site of the electrodes used, since Schneider (1964) has shown that the chronaxie becomes shorter as the electrode site approaches the apex of the ventricle. The present values for threshold energies are in broad agreement with those found by Raillard (1962), J. A. Hopps (1964, personal communication), and Kantrowitz (1964) as well as values found in subsequent patients in whom modified electrodes had been utilized (Davies and Sowton, 1964; Davies, 1965).

\section{Conclusions}

Under the conditions of this investigation the human heart was slightly more sensitive to endocardial than to intramural stimulation, and considerably more sensitive to intramural than to epicardial stimulation.

At the threshold for myocardial contraction, current and voltage varied inversely with impulse duration, the energy being constant over a wide range.

Threshold requirements rose initially for all types of stimulation, but stabilized at fairly low levels in the absence of infection. Final values for threshold energy were approximately 5 microjoules for endocardial stimulation and 20 microjoules for epicardial stimulation; the initial values were about one-tenth of the final values.

The heart showed similar sensitivity to unipolar cathodal stimulation and bipolar stimulation. The threshold for unipolar anodal stimulation was considerably higher.

Voltage and current strength-duration curves for the human heart are presented, and values for rheobase and chronaxie are given.

We wish to thank Dr. Aubrey Leatham and Mr. Harold Siddons for their encouragement and for permission to investigate patients under their care. The work reported here is included in the M.D. Thesis of one of us (E.S.), which has been accepted by the University of Cambridge.

\section{REFERENCES}

Albert, H. M., Glass, B. A., Andonie, J. A., and Cranor, K. C. (1962). Pacemaker failure in complete heart block. Circulat. Res., 10, 295.

$\longrightarrow,-$ Pittman, B., and Robichaux, P. (1964). Cardiac stimulation threshold: chronic study. Ann. N. Y. Acad. Sci., 111, 889.
Brooks, C. McC., Hoffman, B. F., Suckling, E. E., and Orias, O. (1955). Excitability of the Heart. Grune and Stratton, New York.

Chardack, W. M., Gage, A. A., and Greatbatch, W. (1960). A transistorized, self-contained, implantable pacemaker for the long-term correction of complete heart block. Surgery, 48, 643.

$\longrightarrow$ - and - (1961). Correction of complete heart block by a self-contained and subcutaneously implanted pacemaker. Clinical experience with 15 patients. f. thorac. cardiovasc. Surg., 42, 814.

Davies, J. G. (1965). Threshold measurements in pacemaking. In Resuscitation and Cardiac Pacing, ed. G. Shaw, G. Smith, and T. J. Thomson, p. 197. Cassell, London.

- , and Sowton, G. E. (1964). Cardiac pacemakers. Phys. in Med. Biol., 9, 257.

Dittmar, H. A., Friese, G., and Holder, E. (1962). Erfahrungen über die langfristige elektrische Reizung def menschlichen Herzens. Z. Kreisl.-Forsch., 51, 66.

Elmqvist, R., Landegren, J., Pettersson, S. O., Senning, A.., and William-Olsson, G. (1963). Artificial pacemaker for treatment of Adams Stokes syndrome and slow heart rate. Amer. Heart f., 65, 731.

Feldman, D. S. (1963). Excitability of the human heart on endocardial stimulation. Clin. Res., 11, 166.

- , and Kantrowitz, A. (1963). Electrical characteristics of human ventricular myocardium stimulated in vivo. Clin. Res., 11, 22.

Harris, A., Bluestone, R., Busby, E., Davies, G., Leatham, A., Siddons, H., and Sowton, E. (1965). The management of heart block. Brit. Heart F., 27, 469.

Hoffman, B. F., and Cranefield, P. F. (1960). Electrophysiology of the Heart. McGraw-Hill, New York.

- , and - (1964). The physiological basis of cardiac arrhythmias. Amer. F. Med., 37, 670.

Hunter, S. W., Roth, N. A., Bernardez, D., and Noble, J. L. (1959). A bipolar myocardial electrode for complete heart block. F.-Lancet, 79, 506.

Kantrowitz, A. (1964). The treatment of Stokes-Adams syndrome in heart block. Progr. cardiovasc. Dis., 6, 490.

—, Cohen, R., Raillard, H., Schmidt, J., and Feldman, D. S. (1962). The treatment of complete heart block with an implanted, controllable pacemaker. Surg. Gynec. Obstet., 115, 415.

Keller, J. W. (1964). Panel Discussion IV. Ann. N. Y. Acad. Sci., 111, 1105.

Lillehei, C. W., Gott, V. L., Hodges, P. C., Long, D. M., and Bakken, E. E. (1960). Transistor pacemaker for treatment of complete atrioventricular dissociation. F. Amer. med. Ass., 172, 2006.

Mansfield, P. B., and Cole, A. D. (1963). The design and analysis of myocardial electrodes. In Proceedings of the 16th Conference on Engineering in Medicine and Biology.

Nash, D. T. (1964). Threshold of cardiac stimulation: acute studies. Ann. N. Y. Acad. Sci., 111, 877.

-, Neville, J. F., Jr., Grossman, M. A., and Wechsler, L. D. (1962). Electrical characteristics of intraventricular electrodes for myocardial stimulation. Circulation, 26, 767.

Raillard, H. (1962). An implantable cardiac pacemaker. Wld med. Electronics, 1, 41.

Schneider, H. (1964). Physical principles of artificial stimulation of the heart. Stimulation of the canine heart in situ. Amer. Heart f., 67, 628.

Senning, A. (1959). In Discussion of paper by Stephenson et al. (1959), p. 639. 
Siddons, A. H. M. (1963). Long-term artificial cardiac pacing: experience in adults with heart block. Ann. roy. Coll. Surg. Engl., 32, 22.

Simpson, J. A., Gibson, P., Stanford, R. W., and McLernon, D. B. (1962). Prolonged cardiac pacemaking in Stokes-Adams disease. Lancet, 2, 226.

Sowton, E. (1964). Hæmodynamic studies in patients with artificial pacemakers. Brit. Heart F., 26, 737.

- (1965). Artificial pacemaking and sinus rhythm. Brit. Heart f., 27, 311.

-, and Davies, J. G. (1964). Investigation of failure of artificial pacing. Brit. med. F., 1, 1470.

Stephenson, S. E., Jr. (1960). Direct electrical cardiac stimulators. Progr. cardiovasc. Dis., 3, 162.

—, Edwards, W. H., Jolly, P. C., and Scott, H. W., Jr. (1959). Physiologic P-wave cardiac stimulator. $\mathcal{F}$. thorac. Surg., 38, 604.
Tsuboi, S., and Ebina, K. (1960). Studies on the application of rhythmic stimulation for cardiac dysfunction in heart surgery. Bull. Heart Inst. Fap., 4, 1.

Weale, F. E., Deuchar, D. C., and Nightingale, A. (1960). Electrical excitability of the human ventricular myocardium. Guy's Hosp. Rep., 109, 157.

Zarnstorff, W. C., Gott, V. L., Rowe, G. G., and Young, W. P. (1962). Locating the cardiac conduction system by electrical stimulation. Circulation, 26, 807.

Zoll, P. M., Frank, H. A., Zarsky, L. R. N., Linenthal, A. J., and Belgard, A. H. (1961). Long-term electric stimulation of the heart for Stokes-Adams disease. Ann. Surg., 154, 330.

Zucker, I. R., Parsonnet, V., Gilbert, L., and Asa, M. (1963). Dipolar electrode in heart block. f. Amer. med. Ass., 184, 549. 